\title{
O processo ensino-aprendizagem e suas conseqüências na relação professor-aluno-paciente
}

\author{
The teaching-learning process and its consequences \\ to the teacher-student-patient relation
}

\author{
Sharmênia de Araújo Soares Nuto 1 \\ Luiz Roberto Augusto Noro 1 \\ Paola Gondim Cavalsina 2 \\ Íris do Céu Clara Costa 3 \\ Ângelo Giuseppe Roncalli da Costa Oliveira 3
}

\begin{abstract}
This study deals with the ethical and human aspects present in the teaching-learning process within the dentists' formation. It arises from the growing need for professionals involved with the quality of the services they provide for the population in health care centers. In this research a qualitative approach was used and data was obtained by means of focal groups, interviews and participative observation. The sample consisted of 28 dentistry students and 33 patients attended at the dentistry course. According to the results, it was shown that the main problems are the excess of authority in the teacher-student-patient relationship and the dissociation of the body-mind-spirit as seen in the biomedical model health practice. These findings show the future professionals' insufficient abilities for developing a satisfactory relationship with their patients and the need of considering these aspects during their formation.
\end{abstract}

Key words Higher education, Humanism, Dentist-patient relations
Resumo Este estudo versa sobre os aspectos ét $i$ cos e humanos presentes no processo ensinoaprendizagem da formação de cirurgiões-dentistas. Surge a partir do anseio crescente nos serviços de saúde por profissionais mais envolvidos com a qualidade do atendimento à população. Foi utilizada uma abordagem qualitativa tendo três instrumentos de coleta: a técnica de grupo focal, a entrevista semi-estruturada e a observação participante. A amostra foi constituída de 28 alunos de odontologia e 33 pacientes atendidos nas clinicas de cursos de odontologia. A análise do material textual identificou como principais problemas o excesso de autoridade na relação professoraluno-paciente e a separação corpo-mente-espírito presente no modelo biomédico de prática. Esses resultados revelam pouca capacitação dos futuros cirurgiões-dentistas para o desenvolvimento de uma relação dialógica com seus pacientes e a necessidade de repensar esses aspectos na sua formação.

Palavras-chave Educação superior, Humanismo, Relações dentista-paciente

\footnotetext{
1 Faculdade de Odontologia da Unifor. Av. Washington Soares 1321, Edson Queiroz, 60811-905, Fortaleza CE. nuto@unifor.br

2 Probic/Unifor

3 Universidade Federal do Rio Grande do Norte.
} 


\section{Introdução}

Este estudo versa sobre a formação humanista dos cirurgiões-dentistas nos cursos de odontologia. Surge a partir do anseio crescente nos serviços de saúde por profissionais humanos, éticos e compromissados com a qualidade do atendimento à população. Qualidade não apenas do ponto de vista formal da excelência do procedimento executado, mas tendo em vista o que o paciente considera como qualidade e, sobretudo, a partir da relação saudável, cordial e de respeito mútuo.

\section{Formação na saúde}

A maior mudança na medicina ocidental deveu-se à revolução cartesiana, em que a terapêutica baseada na fusão do corpo e da alma foi substituída pelo estudo, tão somente, dos órgãos, células, moléculas e de suas doenças. Quanto maior o aprofundamento científico na compreensão orgânica, maior a dificuldade de associar corpo e mente1.

Essa prática médica, ao longo de sua evolução no mundo capitalista, não modificou a propriedade do saber/fazer, mantendo-se a excessiva valorização da ciência e a intelectualização de saberes, resultando numa relação hierárquica entre profissionais de saúde e pacientes durante o atendimento clínico, reproduzindo as normas sociais da classe dominante, não incorporando no seu contexto aspectos do cuidado humano $2,3,4,5,6$.

Atualmente, a Lei de Diretrizes e Bases da Educação (LDB) e as Diretrizes Nacionais dos Cursos de Graduação em Odontologia ampliaram as proposições colocadas pelo MEC em 1970, a partir da Reforma Universitária. O cirurgião-dentista deverá ter uma formação humanística e ética, para se tornar um profissional habilitado a ser um promotor de saúde, sensibilizado para uma prática odontológica interdisciplinar no âmbito coletivo. Isso pressupõe levar os alunos dos cursos de graduação em saúde a aprender a aprender, o que engloba aprender a conhecer, aprender a fazer, aprender a viver juntos e aprender a ser, garantindo a capacitação de profissionais com autonomia e discernimento para assegurar a integralidade da atenção, a qualidade e a humanização do atendimento prestado aos indivíduos, famílias e comunidades 7,8 .

Segundo Bordenave \& Pereira ${ }^{9}$, a aprendizagem gera mudanças cognitivas, mediatizadas por processos emocionais. Os sentimentos de curiosidade, tensão, ansiedade, angústia, entusiasmo, frustração, alegria, impaciência, obstinação, surgidos no processo ensino-aprendizagem, são importantes e acompanham o ato de perceber, analisar, comparar, entender. Daí se deduz que o aumento de conhecimentos não é apenas quantitativo, baseado no volume de informações acumuladas no cérebro humano, mas a aprendizagem gera simultaneamente mudanças qualitativas que deverão ser trabalhadas integralmente pelo educando.

Para Noro \& Noro ${ }^{10}$, quando o educador respeita a dignidade do aluno e trata-o com compreensão e ajuda construtiva, desenvolve a capacidade do aluno procurar em si mesmo as respostas para seus problemas, tornando-o responsável e, conseqüentemente, agente de seu próprio processo de aprendizagem.

Morin 11 amplia a discussão, estendendo-se além do ensino médico, ao discorrer sobre as modificações necessárias em todo o sistema educacional, para o desenvolvimento de cidadãos capazes de integrar mais harmoniosamente os conhecimentos à condução de suas vidas, na sua relação com o outro, com a sua nação e com o planeta. Assim, defende que a missão do ensino não é somente transmitir o mero saber, mas uma cultura que permita compreender nossa condição e nos ajude a viver, favorecendo um modo de pensar aberto e livre.

Entendendo que o cirurgião-dentista qualificado não é somente aquele com uma excelente habilidade motora, mas, sobretudo, o que é capaz de desenvolver o respeito e responder às ansiedades do paciente, propomos neste trabalho discutir a eficácia do processo de ensinoaprendizagem na formação humanista do cirurgião-dentista e a capacidade deste ensino em aproximá-lo da realidade dos seus pacientes.

\section{Métodos}

A abordagem metodológica qualitativa foi utilizada neste trabalho. Nessa metodologia, a ênfase não é dada à representatividade numérica e aleatória para a generalização da amostra na população, mas à coleta de informações suficientes para a reconstrução do discurso, que permita uma análise aprofundada da subjetividade, envolvendo a questão central do tema pesquisado ${ }^{12}$.

A pesquisa de campo foi realizada em quatro cursos de odontologia no Nordeste, no pe- 
ríodo de fevereiro de 2000 a maio de 2001 . Foram omitidas suas identificações para evitar qualquer comparação entre os mesmos, pois esse não é o objetivo do trabalho.

Trabalhou-se com duas categorias de informantes-chave: a) alunos de odontologia, contatados por professores e colegas de curso; b) pacientes selecionados através da presença do pesquisador na dinâmica de atendimento das clínicas e pelos alunos entrevistados.

Foram realizados entrevistas semi-estruturadas e relatos de "experiências vividas" com as doenças bucais, no que se refere aos usuários; grupos focais e entrevistas semi-estruturadas com os estudantes de odontologia; e observações participantes durante as entrevistas e os grupos focais.

Foi elaborado um roteiro não diretivo para as entrevistas com os pacientes e outro para os grupos focais e entrevistas com os estudantes de odontologia. Os instrumentos eram corrigidos e readaptados durante o processo de trabalho de campo ${ }^{12}$.

As observações participantes não seguiam roteiro prévio, mas era realizada a observação livre sobre conversas informais, comportamentos, gestos, expressões dos alunos e pacientes durante as entrevistas/grupos focais, que dissessem respeito ao tema da pesquisa. As observações eram registradas nos diários de campo dos pesquisadores ${ }^{12}$.

A amostra foi constituída de:

- 28 alunos de odontologia do 6o ao 10o semestre (participantes de quatro grupos focais um em cada faculdade -, em média de seis elementos e de duas entrevistas semi-estruturadas para aprofundamento das questões).

- 33 usuários que freqüentam as clínicas dos cursos de odontologia, que puderam se expressar através de uma entrevista semi-estruturada.

Foi realizado o consentimento informado para todos os participantes dos grupos focais e entrevistas, sendo garantido o sigilo da identificação pessoal e da instituição universitária à qual o informante-chave estava vinculado. Os nomes dos estudantes foram omitidos e os dos usuários foram alterados para preservação de suas identidades.

As entrevistas, os grupos focais e os dados obtidos nos diários de campo através da observação participante foram transcritos, relidos e organizados em um editor de texto. A triangulação das informações foi utilizada para checar a consistência e a validação dos dados 12 .
Após a leitura flutuante, exaustiva e interrogativa para a impregnação de todo o material arquivado, foram construídos dois corpus, reunidos por grupos diferenciados: pacientes e alunos.

Foram realizadas leituras transversais de cada corpus, permitindo a constituição das categorias empíricas, reelaborações e o refinamento das classificações por temas. As categorias empíricas são construídas com finalidade operacional, a partir do trabalho de campo, tendo a propriedade de apreender as determinações e as especificidades da realidade empírica12.

Os temas dos grupos diferenciados foram confrontados entre si, avaliando-se até que ponto o ensino odontológico contribui na formação humanista do cirurgião-dentista, aproximando-o da realidade socioeconômica, cultural e psicológica dos seus pacientes, facilitando o relacionamento interpessoal.

\section{Resultados e discussão}

Foram identificados várias informações e questionamentos, que, após leituras e classificações, foram compilados em quatro grandes temas e suas respectivas categorias empíricas, que serão descritas e ilustradas pelos destaques das falas dos sujeitos amostrais, a saber: cobaias, impor respeito, experiência versus sensibilidade e desrespeito à dor.

\section{Cobaias}

O aluno, durante o atendimento clínico, compõe, juntamente com o paciente e o professor, um relacionamento triangular. Todo o procedimento realizado tem de ser supervisionado pelo professor, ocorrendo demasiada demora na resolução da consulta, o que ocasiona situações embaraçosas para o aluno e o paciente13, 14 .

Ao contrário do que se imagina, os pacientes observam e escutam tudo o que está acontecendo: Às vezes os alunos têm uma dúvida, não sabem o que façam e o professor não está próximo e eles aguardam, ficam naquela dúvida discutindo um com o outro... Vão lá, pegam um TD e dão uma lida e o professor vem e aí acabam de tirar a dúvida (André, 23 anos).

A maioria dos pacientes entrevistados afirmou que confia nos alunos que estão realizando os seus atendimentos e que não se impor- 
tam de serem "cobaias". Entretanto, associam a confiança nos alunos com a "ajudazinha" na fé em Deus: Eu saio de casa e digo: Jesus, tu toma a minha frente, guia a mão daquela moça que vai fazer o tratamento dos meus dentes. Porque eu confio mais em Deus, entrego ela na mão do Senhor, que é pra não haver nada, ser tudo bemsucedido (Rebeca, 50 anos).

Alguns pacientes entrevistados relataram que "se eu sentisse que eles [professores] estavam perto, eu me sentia mais segura" (Paula, 31 anos). Relatos como o de Paula demonstram que a experiência é um critério importante no aumento da segurança e da confiança no dentista.

Entretanto, a maioria dos alunos relatou que possuía pelo menos um paciente com medo dos seus professores, comprovando que a experiência e o acúmulo de conhecimentos não garantem cuidado e atenção ao paciente: $E u$ tentando e sempre dando errado, tentando... Ai eu disse: ah, vou ter que chamar o professor aqui. "Não, tenta de novo, tenta de novo, por favor." Daí eu tentava de novo: vou ter que chamar o professor. "Não, você vai conseguir, não chama o professor não, pelo amor de Deus" (aluno da Clínica Integrada).

Algumas explicações para o "medo do professor" foram explicitadas pelos alunos: desconsideração pelo professor das ansiedades do paciente e do aluno durante o tratamento odontológico; habilidade de realizar os procedimentos mais bruscamente do que o aluno; execução das atividades clínicas mais difíceis, em que o paciente associa a vinda do professor à dor e à repreensão do aluno na frente dele.

Em estudo de Goulart14, foi observado que a qualidade da consulta foi avaliada pelo paciente a partir do cuidado, carinho e atenção, resultando na preferência pelo atendimento com estudantes de medicina em oposição à experiência dos seus professores.

A preocupação maior dos alunos é com algum erro no procedimento técnico e, conseqüentemente, com a avaliação que o professor fará. O bem-estar e o conforto do paciente são considerados em segundo plano.

Essa atitude dos alunos é reforçada quando Ramos ${ }^{15}$ relata que a maioria das clínicas das faculdades possui como alvo principal somente a produção do trabalho técnico, sendo secundário o bem-estar físico e emocional do paciente.

A avaliação do processo ensino-aprendizagem, centrada na produção de uma nota e não desenvolvida como processo - em que o mais importante é o aprimoramento para a melho- ria das habilidades na formação de um cirurgião-dentista em todas as suas dimensões -, dificulta enxergar além de uma boca. Se a escola fracassa em exercer uma ação educativa de respeito à individualidade e ao acompanhamento do desenvolvimento do aluno 16 , como exigir essa atenção do aluno diante do paciente? O receio que eu tenho não é às vezes do paciente, é de, às vezes, talvez cometer algum erro e passar algum professor, porque é todo tempo cobrando: olha a nota, olha a nota (aluno do 6o semestre).

\section{Impor respeito}

O ensino na área da saúde ainda se molda em relações pedagógicas medievais, nas quais o professor é a autoridade máxima, dono do conhecimento e da verdade, e os alunos seguem, sem nenhum questionamento, o que lhe foi proposto, em nome do aprendizado técnico e científico. Tem professor que é tido como muito rigoroso, muito... até mesmo grosso, só falta engolir a gente! Tenta demonstrar medo na gente. Existem professores assim, e eu não aprovo esse tipo de atitude (aluno da Clínica Integrada).

As metodologias pedagógicas da transmissão e condicionamento partem da premissa do "aluno como uma página em branco" e o professor como detentor de conhecimentos e habilidades. Esta forma de ensino estimula a passividade e acentua a competitividade entre os estudantes, sendo a responsável direta pela falta de articulação e mobilização presentes não somente entre os alunos, mas também entre os profissionais de saúde formados nesta base pedagógica $9,17$.

A superioridade do professor tem como conseqüências a baixa auto-estima dos alunos e a reprodução do autoritarismo com seus pacientes: Eu acho que é nervosismo de você estar ali, eu me sinto pressionado por mim mesmo, não queria errar, porque por mais que o professor fale: é fácil, é fácil, é fácil. Não é, pode ser simples, mas fácil não é. Ele chega e diz que é fácil, eu me sinto mais burro, eu fico péssimo toda vez que ele diz que é fácil e eu não consigo fazer, aí eu fico logo todo tremendo e não acerto mais nada (aluno do 7o semestre).

Já tive uma paciente que eu estava fazendo prótese que uma vez ela sentou na cadeira... e disse: mas vocês demoram muito. E eu que estava há quase dois meses com ela, fui dar uns gritos com ela, disse: olha o doutor aqui sou eu, não é você não. Quem sabe o que tem que demorar, o que não tem demorar, sou eu (aluno da Clínica Integrada). 
Você está ali atendendo um paciente e você tem que impor respeito (aluno do 60 semestre).

"Impor" é tornar obrigatório. "Respeito" pode ter os sentidos de: reverência, veneração e obediência, submissão e acatamento18. Em todos os sentidos, quando utilizado na relação dentista-paciente, "respeito" demonstra superioridade e autoritarismo.

A questão do autoritarismo do professor na relação com seus alunos perpassa a dimensão da subjetividade e da identidade deste professor universitário, que em muitos casos não tem formação, nem tampouco vocação pedagógica, reproduzindo de forma intuitiva ou autodidata apenas o modelo biomédico no qual foi formado. Isso se explica devido à inexistência de uma formação específica como professor universitário, predominando, desta forma, na maioria das instituições de ensino superior, o desconhecimento científico do que seja o processo de ensino e de aprendizagem ${ }^{19}$.

Para Branden ${ }^{20}$, quando os professores apresentam baixa auto-estima, quase sempre há preferência às táticas destrutivas e humilhantes para manter o controle da classe e acabam por aumentar os problemas de auto-estima que os alunos já têm.

Esse modelo autoritário de ensinar foi sendo construído e passado de geração a geração para os futuros professores, sem que se fizesse uma reflexão sobre a práxis do processo de ensino-aprendizagem, nas escolas médicas. Atualmente, essa discussão já vem ocorrendo, gerando reformulações curriculares em vários cursos da área da saúde disseminados por todo o país.

O aumento da autoconfiança do aluno melhora os desempenhos técnicos e humanos. $\mathrm{O}$ diálogo e a relação igualitária, em que o professor tenha habilidade de criticar e elogiar com estímulo, facilita o processo ensino-aprendizagem. Os alunos relatam a preferência: $E$ a questão do diálogo, se é aberto ou não. Determinados professores, não é que eles estejam no mesmo nível do aluno, mas eles se colocam, eles têm uma abertura, que permite você tirar uma dúvida; muitas vezes você está num procedimento e você sabe, mas não tem certeza, você sente a necessidade de discutir aquilo com o professor (aluno do 7 o semestre).

López $^{21}$ relata que o objetivo maior do ensino médico é formar profissionais competentes, humanos e compassivos, sendo importante que o processo ensino-aprendizagem esteja composto de elementos cognitivos e afetivos.
No cognitivo, o aluno possui uma maior abertura para tirar suas dúvidas sem receio de ser repreendido, desenvolvendo segurança durante as atividades clínicas. No afetivo, possibilita a transferência dessa boa relação ao paciente. $\mathrm{Pa}$ ra isso, é fundamental o desenvolvimento do diálogo e da auto-estima na relação professoraluno, buscando-se o equilíbrio psicoemocional e ambiental do educando 22 .

\section{Experiência versus sensibilidade}

A necessidade do desenvolvimento de aspectos humanísticos na relação aluno-paciente durante o período de práticas clínicas foi confirmada por todos os alunos entrevistados, pois o conteúdo da disciplina de psicologia é distante da realidade dos atendimentos.

A odontopediatria é citada como uma das poucas disciplinas clínicas que desenvolvem temas relacionados com as estratégias de atendimento aos pacientes, mas com o objetivo maior de condicionar a criança e ela colaborar na realização do tratamento. Geralmente você se volta muito para criança. Você acaba esquecendo um pouco que o idoso, e até mesmo o adulto, também tem medo (aluno da Clínica Integrada).

Nos alunos das Clínicas Integradas foi observada uma menor sensibilização. É importante que essa realidade seja enfrentada pelos cursos de odontologia, pois se detecta com isso que está sendo produzida uma dessensibilização dos alunos ao longo do tempo de formação acadêmica. No estudo realizado por Berlinguer (1987), citado por Goulart14, foi observado um processo semelhante, ocorrendo uma diminuição gradativa na qualidade das relações alunopaciente, ocasionada pelo ensino médico: $E u$ lembro que logo no começo eu tinha a mania de dar bom dia ou boa tarde... Caminhava com o paciente, perguntava como é que ele estava. Mas você vai perdendo, às vezes eu chego lá não vejo nem onde ele está, não digo nem oi, nem bom dia, nem nada... Você vai ganhando experiência, você vai se acostumando com aquilo, o profissional vai perdendo a sensibilidade (aluno da Clínica Integrada).

Uma das maiores preocupações apresentadas por alunos no início das clínicas foi a possibilidade de perder, com o passar do tempo, a preocupação com o paciente, que eles têm hoje, ou seja, esquecer as ansiedades, receios, traumas do paciente e banalizar o ato clínico, apesar de toda parafernália de equipamento, material e instrumental que por si só o assus- 
tam. Em alguns alunos há uma preocupação com o bem-estar do paciente. Eles possuem a capacidade empática de se colocar no lugar do outro e compreender as dificuldades de ser submetido ao tratamento odontológico: Não só pela falta de habilidade, experiência, mas também por a gente ser novo ainda. A gente está começando, a gente se preocupa em ser delicado com o paciente, se preocupa em não causar nenhum tipo de desconforto... Eu tenho medo de perder essas preocupações, como a maioria dos meus professores demonstra ter perdido isso (aluno do 6 o semestre). Depois que você passa por uma situação aí você sabe... Foi extraído em mim um terceiro molar que o CD não usou [anestésico tópico], aí você vê a diferença e nunca mais você deixa de usar em um paciente. Eu passei por uma situação de um anestésico injetado rápido, falta de anestésico tópico, e você sente um desconforto terrivel. Depois que eu passei por isso não tem nem perigo de eu não usar um tópico num paciente, que é muito ruim (aluno da Clínica Integrada).

Essa habilidade foi desenvolvida por aspectos intrínsecos às suas experiências pessoais; não é produto de conteúdos cognitivos desenvolvidos na graduação, e foi aguçada, nos relatos dos alunos, devido a duas situações: vivência de ser paciente e medo de dentista quando criança (dentista-ferido).

Alguns médicos, que refletiram sua prática a partir de suas vivências como doentes (médico-ferido), são incisivos nas afirmações que a história passada e o apoio moral e psicológico ao paciente são desconsiderados na maioria dos atendimentos médicos 5 .

\section{Desrespeito à dor}

A integralidade parafraseada em $o$ indivíduo não é só uma boca, utilizada repetidamente pelos alunos na busca de demonstrar uma visão do ser biopsicosocial, é, na verdade, entendida simplesmente como "as doenças sistêmicas do paciente": A habilidade de ver o paciente como um todo, esquecer que estamos trabalhando só na boca e ver o organismo como um todo, se tiver um paciente diabético, hipertenso, não só também em relação à boca (aluno da Clínica Integrada).

Nos grupos focais e nas entrevistas realizadas foi observado que todos os alunos participantes identificam os pacientes ansiosos e que possuem algum temor em relação ao dentista. Eles relataram essa identificação através das reações do paciente na cadeira odontológica: paciente suando; que pergunta muito; que olha muito o instrumental; que reclama de tudo; que tudo dói; que começa a se mexer demais e ficar inquieto na cadeira; o jeito com as mãos segurando firme na cadeira ou pedem pra ir ao banheiro.

Os depoimentos dos alunos fortalecem a capacidade que possuem de estabelecer uma comunicação com os pacientes, em alguns momentos bastante satisfatória, mas sem compreender o que foi realizado. E, no momento da dor, em última instância, o paciente está sempre "mentindo", "fazendo charme" ou "com manha".

A dor ou ela existe ou ela é inventada. Se ela é inventada que a gente desconsidere (aluno da Clínica Integrada).

Existe uma pessoa muito boa, capacidade assim fantástica, mas que do "oi, tudo bem" ao "tchau, paciente", ele não tem dó de algumas coisas não, então eu já cansei de ver algumas vezes o paciente reclamando de dor e ele continuando sem parar (aluno da Clínica Integrada).

Infelizmente, a odontologia está histórica e culturalmente associada à dor e ao sofrimento, quando nos seus primórdios não se dispunha de anestesia e de outros insumos que trazem conforto ao paciente. Para exemplificar, temos a situação relatada por um aluno do último ano, em que comenta o medo do paciente das canetas de alta e baixa rotação e a solução para o problema: Eu me lembro que eu peguei uma paciente que eu ligava o motorzinho de baixa rotação e ela dava uns gritos na cadeira. Então já com a cureta ela não dizia nada, mas eu fiz um teste, peguei o baixa [rotação] e ela fez igual à criança, acionei o motor mas não coloquei no dente dela, deixei só dentro da boca e ela gritando. Aí eu parei, disse que o dente dela estava anestesiado, que eu não estava fazendo nada com o dente dela, que eu estava só fazendo um teste, $e$ ela ficou com os olhos arregalados assim: "Não, mas está doendo, está doendo.” É não, era só psicológico (aluno concluinte).

A expressão "é só psicológico" foi utilizada repetidamente pelos alunos como justificativa para a realização dos procedimentos odontológicos, mesmo com afirmações insistentes de desconforto dos pacientes, desconsiderando outros aspectos que também contribuem para o medo. A pouca importância dada ao "medo de dentista" reforça mais uma vez a separação corpo-mente-espírito presente no modelo biomédicol. 
Eu tenho medo porque na minha impressão, o motor vai furar até o fim do dente e vai chegar até o queixo. Eu penso logo no pior, eu digo logo: tá doendo. Porque na minha mente está furando tudo, está furando mais do que já estava (d. Sônia, 28 anos).

\section{Considerações finais}

O estudo do material de campo levantou alguns problemas na formação de cirurgiõesdentistas, revelando a pouca capacitação para o desenvolvimento de uma relação dialógica com seus pacientes.

O autoritarismo presente na relação professor-aluno e a baixa auto-estima proporcionada pelo processo de ensino-aprendizagem dificultam o desenvolvimento afetivo do aluno consigo mesmo, com os colegas e pacientes, pois a reprodução do autoritarismo como "modelo ideal" é evidente.

Agravando ainda mais essa situação, a dicotomia corpo-mente é reproduzida nos currículos tradicionais, pois as disciplinas clínicas e humanas estão separadas, gerando um proces- so de dessensibilização progressiva dos alunos durante a graduação, em que o maior empenho é para o desenvolvimento das habilidades técnicas e motoras.

Para a superação dessas dificuldades, além da incorporação pelo professor de um novo referencial pedagógico, em que a construção do conhecimento seja compartilhada com o aluno, através de metodologias ativas de aprendizagem, deverão ser consideradas as novas diretrizes curriculares e a integração curricular. Nesse modelo pedagógico, a ênfase é dada à integração entre os conteúdos humanos e técnicos, desenvolvendo-se aspectos humanísticos durante as diversas atividades clínicas, em que o aluno deveria estar atendendo os pacientes e ao mesmo tempo vivenciando e teorizando sobre suas dificuldades na relação interpessoal.

Espera-se que os resultados aqui expostos possam servir de problematização da realidade vivida por muitos cursos de odontologia do Brasil, e que gerem um processo de reflexão e incorporação do referencial teórico das diretrizes curriculares nos seus respectivos projetos pedagógicos.

\section{Colaboradores}

SAS Nato e PG Calvasina participaram da pesquisa, revisão bibliográfica e da redação final. LRA Noro participou da revisão bibliográfica e da redação final; e ICC Costa e AGRC Oliveira participaram da redação final.

\section{Agradecimentos}

Aos colegas Hudson Juliano Bandeira Barbosa, Priscila Belchior de Souza Fernandes, Raphael Araújo de Pontes Medeiros, Renata de Araújo Coelho e Roberta Matos Feitosa, que, pela dedicação e compromisso, contribuíram na pesquisa de campo e nos ricos momentos de discussão.

\section{Referências}

1. Capra F. O ponto de mutação.15a ed. São Paulo: Cultrix; 1993.

2. Luz MT. As instituições médicas no Brasil: instituição e estratégia de hegemonia. 3a ed. Rio de Janeiro: Graal; 1986.

3. Ramos CL, Melo JA, Soares JC. Quem educa quem? Repensando a relação médico-paciente. In: Costa NR, Ramos CL, Minayo MC, Stotz EN, organizadores. Demandas populares, políticas públicas e saúde. Petrópolis: Vozes; 1989. p. 145-64.

4. Schraiber LB. O médico e seu trabalho: limites da liberdade. São Paulo: Hucitec; 1993.

5. Caprara A, Franco AL. A relação paciente-médico: para uma humanização da prática médica. Cad Saúde Pública 1999; 15:647-54.

6. Grosseman S, Patrício ZM. A relação médico-paciente e o cuidado humano: subsídios para a promoção da educação médica. RBEM 2004; 28:99-104.

7. Brasil. Ministério da Educação. Diretrizes Nacionais do Curso de Graduação em Odontologia. Resolução CNE/CES 3, de 19 de fevereiro de 2002. Diário Oficial da União. 4 de março de 2002, seção 1, p. 10. 
8. Costa ICC. Planejamento das ações de saúde. In: Ferreira MAF, Roncalli AG, Lima KC, organizadores. Saúde bucal coletiva: conhecer para atuar. Natal: Ed. da UFRN; 2005.

9. Bordenave JD, Pereira AM. Estratégias de ensinoaprendizagem. 19a ed. Petrópolis: Vozes; 1998.

10. Noro EMS, Noro LRA. A auto-estima como facilitador do processo ensino-aprendizagem. Revista de $\mathrm{Hu}$ manidades 2002; 17:113-9.

11. Morin E. A cabeça bem-feita: repensar a reforma, reformar o pensamento. Rio de Janeiro: Bertrand Brasil; 2000.

12. Minayo MC. O desafio do conhecimento: pesquisa qualitativa em saúde. 4a ed. São Paulo: Hucitec; Rio de Janeiro: Abrasco; 1996.

13. Martins $\mathrm{C}$, organizador. Perspectivas da relação médico-paciente. 2a ed. Porto Alegre: Artes Médicas; 1981

14. Goulart LMH. "Depois que forma, muda": estudo da relação médico-paciente no âmbito da prática docente-assistencial na Faculdade de Medicina-UFMG. In: Paiva A, Soares M, organizadores. Universidade, cultura e conhecimento: a educação pesquisa a UFMG. Belo Horizonte: Autêntica; 1998. p. 231-49
15. Ramos FB. Como o paciente se sente ao ser atendido por um aluno de odontologia? Revista do CROMG 2001; 7:10-15.

16. Hoffmann J. Pontos \& contrapontos: do pensar ao agir em avaliação. 7ạ ed. Porto Alegre: Mediação; 2003.

17. Wierzchon PM. O ensino médico está mudando? Transpondo desafios para concretizar mudanças. RBEM 2002; 26:62-66.

18. Ferreira $\mathrm{ABH}$. Novo dicionário da língua portuguesa. 2a ed. Rio de Janeiro: Nova Fronteira; 1986.

19. Pimenta SG, Anastasiou LGC. Docência no ensino superior. São Paulo: Cortez; 2002.

20. Branden N. Auto-estima e seus pilares. $5 \underline{a}$ ed. São Paulo: Saraiva; 2000.

21. López M. Fundamentos da clínica médica: a relação paciente-médico. Rio de Janeiro: Medsi; 1997.

22. Castro FC. Os temores na formação e prática da medicina: aspectos psicológicos. RBEM 2004; 28:38-45.

Artigo apresentado em 27/06/2005

Aprovado em 15/08/2005

Versão final apresntada em 2/09/2005 